\title{
Global Sourcing of Low-Inorganic Arsenic Rice Grain
}

\author{
Manus Carey ${ }^{1} \cdot$ Caroline Meharg $^{1} \cdot$ Paul Williams $^{1} \cdot$ Ernest Marwa $^{2} \cdot$ Xiao Jiujin $^{1,3} \cdot$ Júlia Gomes Farias $^{1,4}$. \\ P. Mangala C. S. De Silva ${ }^{5}$. Antonio Signes-Pastor ${ }^{1} \cdot$ Ying Lu $^{6}$. Fernando Teixeira Nicoloso ${ }^{4} \cdot$ Laurie Savage $^{1}$. \\ Katrina Campbell ${ }^{1}$. Christopher Elliott ${ }^{1}$. Eureka Adomako ${ }^{7}$. Andy J. Green ${ }^{8}$. Eduardo Moreno-Jiménez ${ }^{9}$. \\ Ángel Antonio Carbonell-Barrachina ${ }^{10}$. Eridha Ayu Triwardhani ${ }^{1}$. Febbyandi Isanda Pandiangan ${ }^{1} \cdot$ Parvez I. Haris $^{11}$. \\ Youssef F. Lawgali ${ }^{12}$. Alessia Sommella ${ }^{13}$. Massimo Pigna ${ }^{13} \cdot$ Catherine Brabet $^{14} \cdot$ Didier Montet $^{14} \cdot$ Keston Njira $^{15}$. \\ Michael J. Watts ${ }^{16} \cdot$ Andrew A. Meharg $^{1}$ (i)
}

Received: 22 August 2019 / Revised: 21 October 2019 / Accepted: 29 October 2019 / Published online: 12 November 2019

(c) The Author(s) 2019

\begin{abstract}
Arsenic in rice grain is dominated by two species: the carcinogen inorganic arsenic (the sum of arsenate and arsenite) and dimethylarsinic acid (DMA). Rice is the dominant source of inorganic arsenic into the human diet. As such, there is a need to identify sources of low-inorganic arsenic rice globally. Here we surveyed polished (white) rice across representative regions of rice production globally for arsenic speciation. In total 1180 samples were analysed from 29 distinct sampling zones, across 6 continents. For inorganic arsenic the global $\tilde{x}$ was $66 \mu \mathrm{g} / \mathrm{kg}$, and for DMA this figure was $21 \mu \mathrm{g} / \mathrm{kg}$. DMA was more variable, ranging from $<2$ to $690 \mu \mathrm{g} / \mathrm{kg}$, while inorganic arsenic ranged from $<2$ to $399 \mu \mathrm{g} / \mathrm{kg}$. It was found that inorganic arsenic dominated when grain sum of species was $<100 \mu \mathrm{g} / \mathrm{kg}$, with DMA dominating at higher concentrations. There was considerable regional variance in grain arsenic speciation, particularly in DMA where temperate production regions had higher concentrations. Inorganic arsenic concentrations were relatively consistent across temperate, subtropical and northern hemisphere tropical regions. It was only in southern hemisphere tropical regions, in the eastern hemisphere that low-grain inorganic arsenic is found, namely East Africa $(\tilde{x}<10 \mu \mathrm{g} / \mathrm{kg})$ and the Southern Indonesian islands $(\tilde{x}<20 \mu \mathrm{g} / \mathrm{kg})$. Southern hemisphere South American rice was universally high in inorganic arsenic, the reason for which needs further exploration.
\end{abstract}

Keywords Arsenic $\cdot$ Global $\cdot$ Rice

Andrew A. Meharg

aa.meharg@qub.ac.uk

1 Biological Sciences, Institute for Global Food Security, Queen's University Belfast, 19 Chlorine Gardens, Belfast BT9 5DL, Northern Ireland, UK

2 Department of Soil \& Geological Sciences, Sokoine University of Agriculture, P. O. Box 3008, Morogoro, Tanzania

3 Sichuan Agricultural University, Chengdu 611130, Sichuan, People's Republic of China

4 Departamento de Biologia, Centro de Ciências Naturais E Exatas, Universidade Federal de Santa Maria, Santa Maria, RS 97105-900, Brazil

5 Department of Zoology, University of Ruhuna, Matara 81000, Sri Lanka

6 College of Natural Resources and Environment, South China Agricultural University, Guangzhou 510642, China

7 Department of Plant and Environmental Biology, University of Ghana, P. O. Box LG 55, Legon, Accra, Ghana
8 Department of Wetland Ecology, Estación Biológica de Doñana-CSIC, C/ Américo Vespucio s/n, 41092 Sevilla, Spain

9 Department of Agricultural and Food Chemistry, Faculty of Sciences, Universidad Autónoma de Madrid, 28049 Madrid, Spain

10 Grupo Calidad Y Seguridad Alimentaria, Departamento Tecnología Agroalimentaria, Universidad Miguel Hernández de Elche, 03312 Orihuela, Alicante, Spain

11 Faculty of Health \& Life Sciences, De Montfort University, Leicester LE1 9BH, UK

12 Faculty of Biomedical Sciences, University of Benghazi, Benghazi, Libya

13 Dipartimento Di Agraria, Università Degli Studi Di Napoli Federico II, Via Università 100, 80055 Portici, NA, Italy

14 CIRAD, UMR Qualisud, TA B95/16, 73 rue Jean-François Breton, 34398 Montpellier Cedex 5, France

15 Lilongwe University of Agriculture and Natural Resources, P.O. Box 219, Lilongwe, Malawi

16 British Geological Survey, Keyworth, Nottingham NG12 5GG, England, UK 


\section{Introduction}

Paddy rice is the dominant source of the carcinogen inorganic arsenic to the human diet (EFSA 2009; EU 2015; WHO 2014). The concentrations of inorganic arsenic in rice are of such concern that both the WHO (2014) and EU (2015) have set Maximum Levels (MLs). Identifying where and why rice is low in arsenic is important for developing strategies to lower inorganic arsenic in the diet. Regional studies have shown that with respect to regulation of arsenic species in rice grain that there is a complex interaction between plant physiology and genetics, soil biogeochemical cycling, paddy management practice, natural bedrock geology and soil diagenesis and environmental contamination (Meharg and Zhao 2012). In particular, point source paddy contamination through mine spoil contamination (Zhu et al. 2008), other industrial activity ( $\mathrm{Li}$ et al. 2015) and coal burning ( $\mathrm{Li}$ et al. 2015) have all been identified as major sources of soil pollution. Irrigation can be important source of arsenic to paddy fields, such as for the Bengal Delta where elevated groundwaters are used for dry season rice cultivation (Williams et al. 2006).

Arsenic, generally, is either naturally or anthropogenically inputted into soils in the inorganic state. Under paddy conditions soil microflora can convert inorganic arsenic to methylated species (Reid et al. 2017), with the dimethylarsinic acid (DMA) so produced being readily translocated to grain (Carey et al. 2010). Geographically, the relative contribution of inorganic arsenic and DMA to grain arsenic is known to vary considerably, with higher concentrations of DMA observed in temperate growing regions (Meharg et al. 2009; Zavala et al. 2008), though the reasons underpinning this variation are not known.

To gain a better understanding of the variation in rice grain arsenic there is a need to determine if there are any global patterns and trends across the growing regions of this crop. In particular, this needs integration of S. American, African and the S.E. Asian archipelago that are either under reported in the literature, or only feature in interregional comparisons to a limited extent (Adeyemi et al. 2017; Adomako et al. 2011; Farias et al. 2015; Joy et al. 2017; Otero et al. 2016; Segura et al. 2016). This knowledge is required to source low arsenic rice for sub-populations where the consumption of inorganic arsenic from rice is of particular concern, such as for infants and young children (Carey et al. 2018). Here we set out to determine the variation in rice grain arsenic concentrations and speciation across representative growing regions globally. Twenty-nine cultivation regions, across 6 continents, that spanned the world's major paddy rice growing areas, were selected and market polished (white) rice (to reflect actual dietary consumption) were analysed for arsenic speciation.

\section{Materials and Methods}

\section{Rice Sample Collection}

Polished, locally produced, market rice, $n=1180$, was purchased from retailers from 29 distinct sampling regions from 6 continents. Surveyed regions and sampling frequency are given in Table 1, and mapped in Fig. 1. Given the variability in rice post-harvest processing and how rice is distributed and retailed from country to country, and the geographic scale of the task (i.e. covering all rice global regions systematically is not possible without enormous resource), approaches to rice collection are dependent on the location and geographic reach of collaborating scientists. Accessible market stalls and supermarkets were targeted to source rice. Also, sample density per region varied as well (Table 1). All, this must be born in mind with respect to the interpretation of the data. This sampling approach is comparable with previous literature publications on market rice arsenic (Meharg et al. 2009; Zavala et al. 2008). Where possible (that sampling density supported the sub-division of samples), data were collated within regional blocks for geographically large rice growing regions such as Brazil, Spain and Vietnam. Sampling structure and density is outlined in Table 1.

\section{Sample Preparation}

Rice samples were freeze dried and then milled to a fine powder using a Retsch Planetary ball-mill (Germany), lined with a zirconium oxide coated grinding chamber and milling balls. For As speciation freeze-dried milled rice was weighed accurately to a weight of $0.1 \mathrm{~g}$ into $50 \mathrm{ml}$ polypropylene centrifuge tubes to which $10 \mathrm{ml}$ of $1 \%$ conc. Aristar nitric acid was added and allowed to sit overnight. Batches of up to 48 samples were prepared which also included 2 blanks and 2 rice flour CRM NIST 1568b in all analytical batches. Samples were then microwave digested in an CEM MARS 6 instrument for $30 \mathrm{~min}$. at $95{ }^{\circ} \mathrm{C}$ using a 3 -stage slow heating programme: to $55^{\circ} \mathrm{C}$ in $5 \mathrm{~min}$. held for $10 \mathrm{~min}$., to $75^{\circ} \mathrm{C}$ in $5 \mathrm{~min}$., held for $10 \mathrm{~min}$. to $95{ }^{\circ} \mathrm{C}$ in $5 \mathrm{~min}$., held for $30 \mathrm{~min}$. The digestate, on cooling, was accurately diluted to $10 \mathrm{ml}$ with deionized distilled water and centrifuged at $4500 \mathrm{rpm}$ for $15 \mathrm{~min}$. A $1 \mathrm{ml}$ aliquot was transferred to a $2 \mathrm{ml}$ polypropylene vial and $10 \mu \mathrm{l}$ of analytical grade hydrogen peroxide was added to convert any arsenite to arsenate to facilitate subsequent chromatographic detection. The NIST rice flour CRM NIST $1568 \mathrm{~b}$ was included in each batch of rice tissues to ascertain percentage recoveries, and reagent blanks were also included, as per arsenic speciation. 


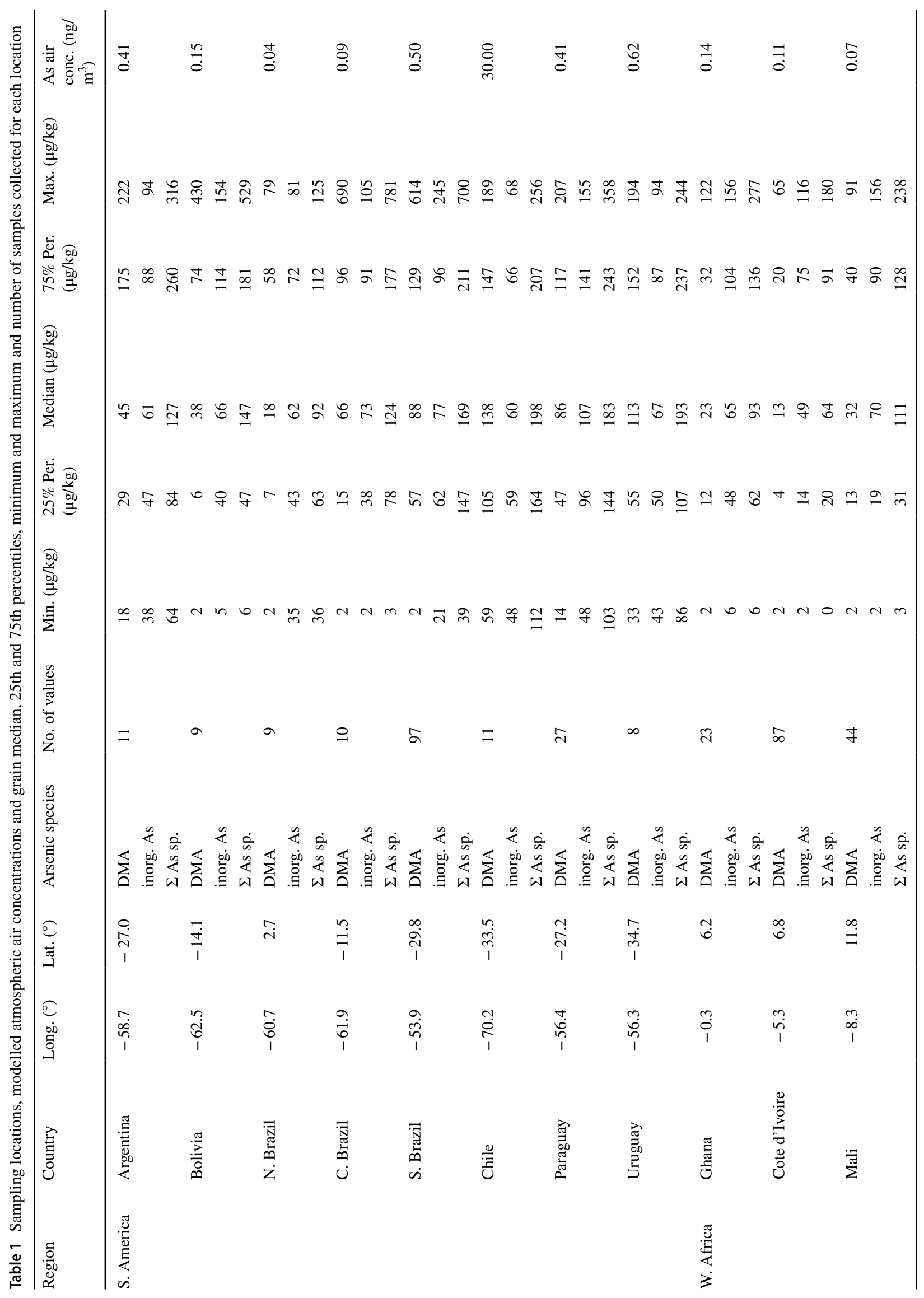




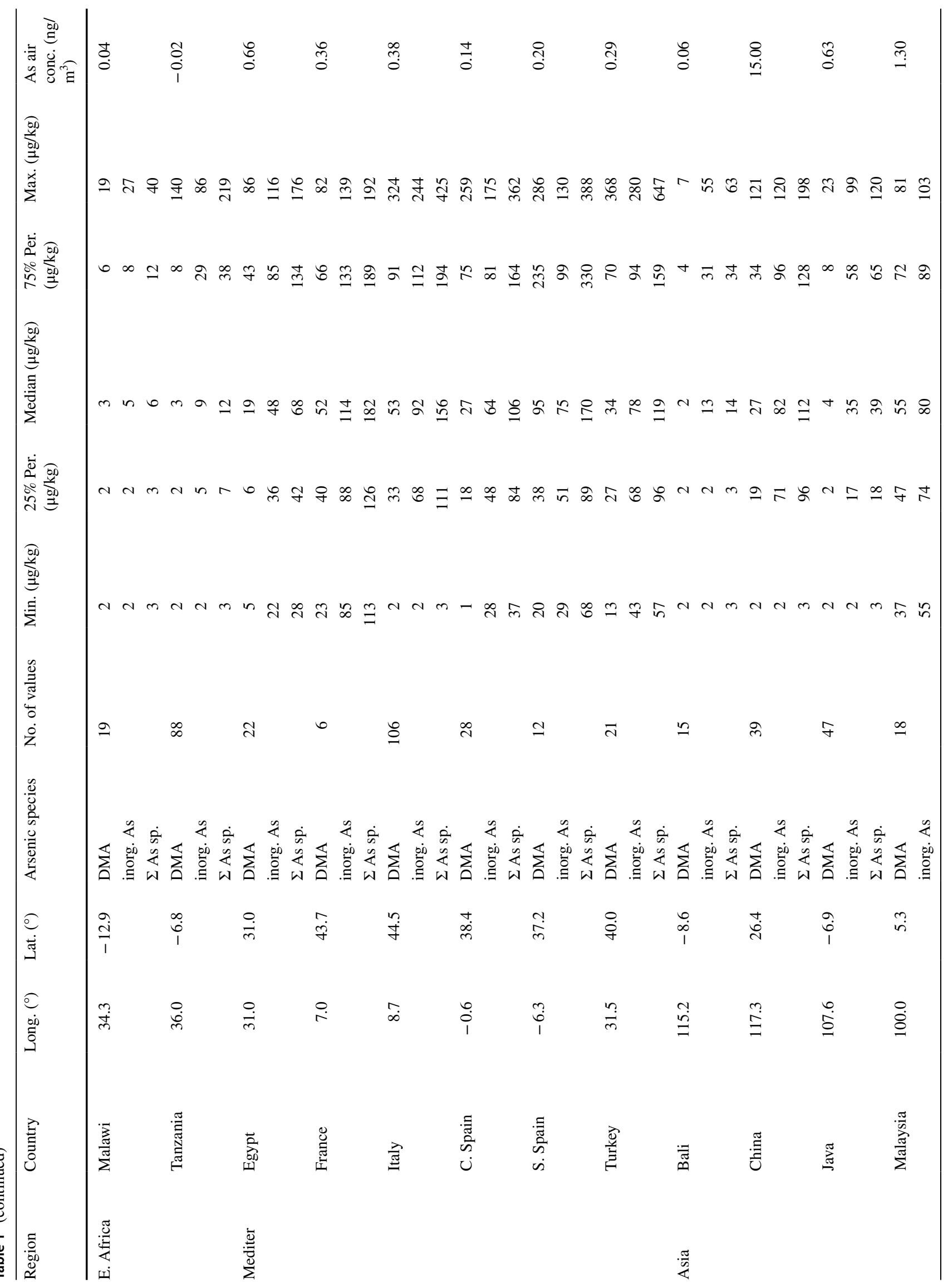




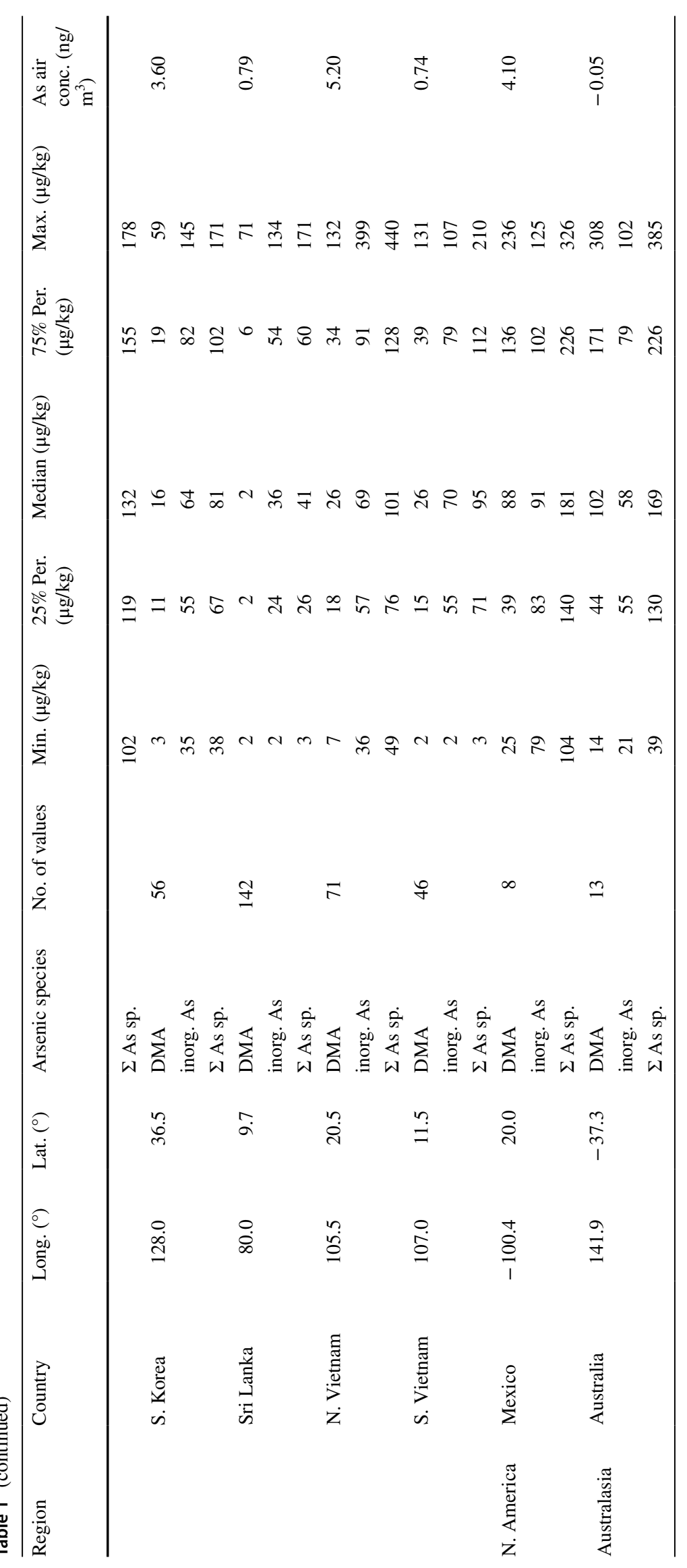




\section{Chemical Analysis}

To speciate As in rice the digested rice solutions were analysed using a Thermo Scientific IC5000 Ion Chromatography (IC) system, with a Thermo AS7, $2 \times 250 \mathrm{~mm}$ column (and a Thermo AG7, $2 \times 50 \mathrm{~mm}$ guard column), with a gradient mobile phase (A: $20 \mathrm{mM}$ ammonium carbonate, B: $200 \mathrm{mM}$ ammonium carbonate-starting at $100 \% \mathrm{~A}$, changing to $100 \% \mathrm{~B}$, in a linear gradient over $15 \mathrm{~min}$., with a flow rate of $0.3 \mathrm{ml} / \mathrm{min}$ ), interfaced with a Thermo ICAP Q ICP-MS that monitored $\mathrm{m} / \mathrm{z}^{+} 75$, using $\mathrm{He}$ gas in collision cell mode. The resulting chromatogram was compared with that for authentic standards; DMA, arsenate, monomethylarsonic acid, tretramethylarsonium and arsenobetaine. The arsenic present under each chromatographic peak was calibrated using a DMA concentration series. This calibration was also used to calculate the Limits of Detection (LoD). The rice flour CRM NIST 1568b was used in all rice speciation analytical batches $(n=76)$, with DMA have $100 \pm 2.7 \%$ median and standard error recovery; and inorganic arsenic $99 \pm 1.1 \%$ recovery. LoD was $3 \mu \mathrm{g} / \mathrm{kg}$ for grain inorganic arsenic and DMA.

\section{Statistical Analysis}

All statistical analysis was performed on SPSS v. 25. The Kruskal-Wallis test was used to test medians between sample groups.

\section{Results}

Globally, inorganic arsenic in polished rice varied from $<2$ to $399 \mu \mathrm{g} / \mathrm{kg}$, with a global median $(\tilde{x})$ of $66 \mu \mathrm{g} / \mathrm{kg}$ (Table 1 ; Fig. 1). Median values significantly varied between regions $(P<0.0001)$. The lowest inorganic arsenic rice region was East Africa with Malawi and Tanzania having $\tilde{x}$ concentrations of 5 and $9 \mu \mathrm{g} / \mathrm{kg}$, respectively. West African rice had circa an order of magnitude higher inorganic arsenic than East African, with the main West African regions being in the northern hemisphere, and East African in the southern hemisphere (Fig. 1). The only other region that approached East Africa with respect to low arsenic concentrations were in the equatorial, southern hemisphere locations of Bali $(\tilde{x}=13 \mu \mathrm{g} / \mathrm{kg})$ and Java $(\tilde{x}=35 \mu \mathrm{g} / \mathrm{kg})$. South American rice was universally high in inorganic arsenic, not showing the trend observed for Africa and Asia where concentrations decreased towards the equator.

The global $\tilde{x}$ for DMA in rice, $21 \mu \mathrm{g} / \mathrm{kg}$, was a third that of inorganic arsenic (Fig. 1). However, DMA was more variable in rice as compared to inorganic arsenic, with DMA in grain ranging from $<2$ to $690 \mu \mathrm{g} / \mathrm{kg}$. Medians between regions were significantly different $(P<0.0001)$. Temperate regions tended to have higher DMA than subtropical, and
A
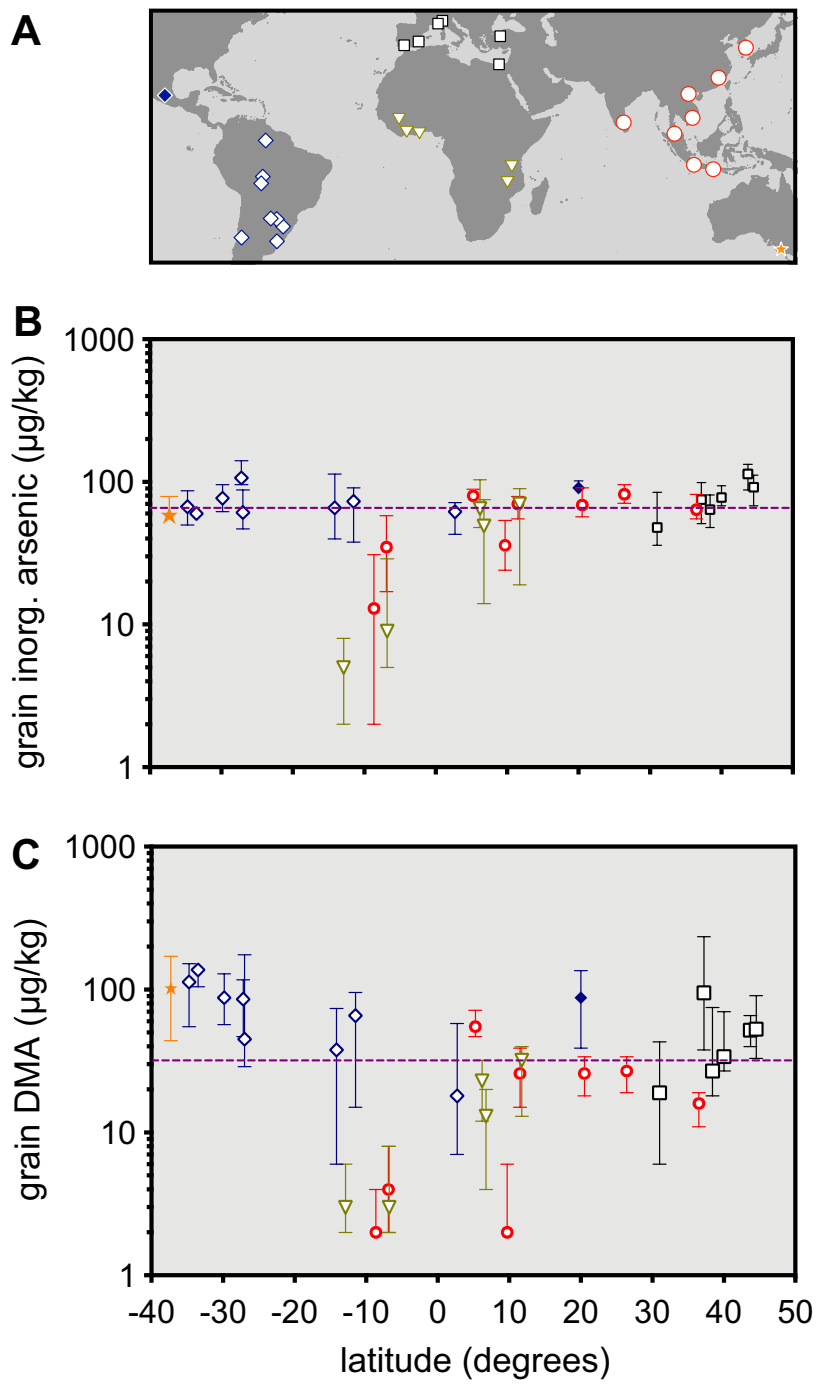

Fig. 1 Centroid locations of the 29 sampling areas (a). Concentrations of arsenic species in white (polished) rice across the globe, median concentrations of inorganic arsenic (b) and DMA (c) in grain at each location, plotted by latitude, with a gold star for Australia, blue diamond for the America's, green inverted triangle for Africa, red circle for Asia, black square for Mediterranean. Bars represent the 25 th and 75 th percentiles. The purple dashed line is the median for the 29 regions

then decreasing considerably in southern hemisphere tropical regions. Northern equatorial regions tended to have intermediate DMA concentrations, around the global median. The major outlier with respect to grain DMA was Sri Lankan rice with $\tilde{x}=2.0 \mu \mathrm{g} / \mathrm{kg}$, but had a typical inorganic arsenic profile for the latitude at $24 \mu \mathrm{g} / \mathrm{kg}$. Tropical southern hemisphere rice, East African and Indonesian, were very low in DMA with $\tilde{x}$ 's $<5 \mu \mathrm{g} / \mathrm{kg}$. West African and northern Indonesian rice had DMA $>10 \mu \mathrm{g} / \mathrm{kg}$. South America showed the shallowest cline in DMA with temperate/subtropical South American rice DMA being, $\tilde{x}>40 \mu \mathrm{g} / \mathrm{kg}$, decreasing to $\tilde{x}=18 \mu \mathrm{g} / \mathrm{kg}$ in northern Brazil (Fig. 1). North American, 

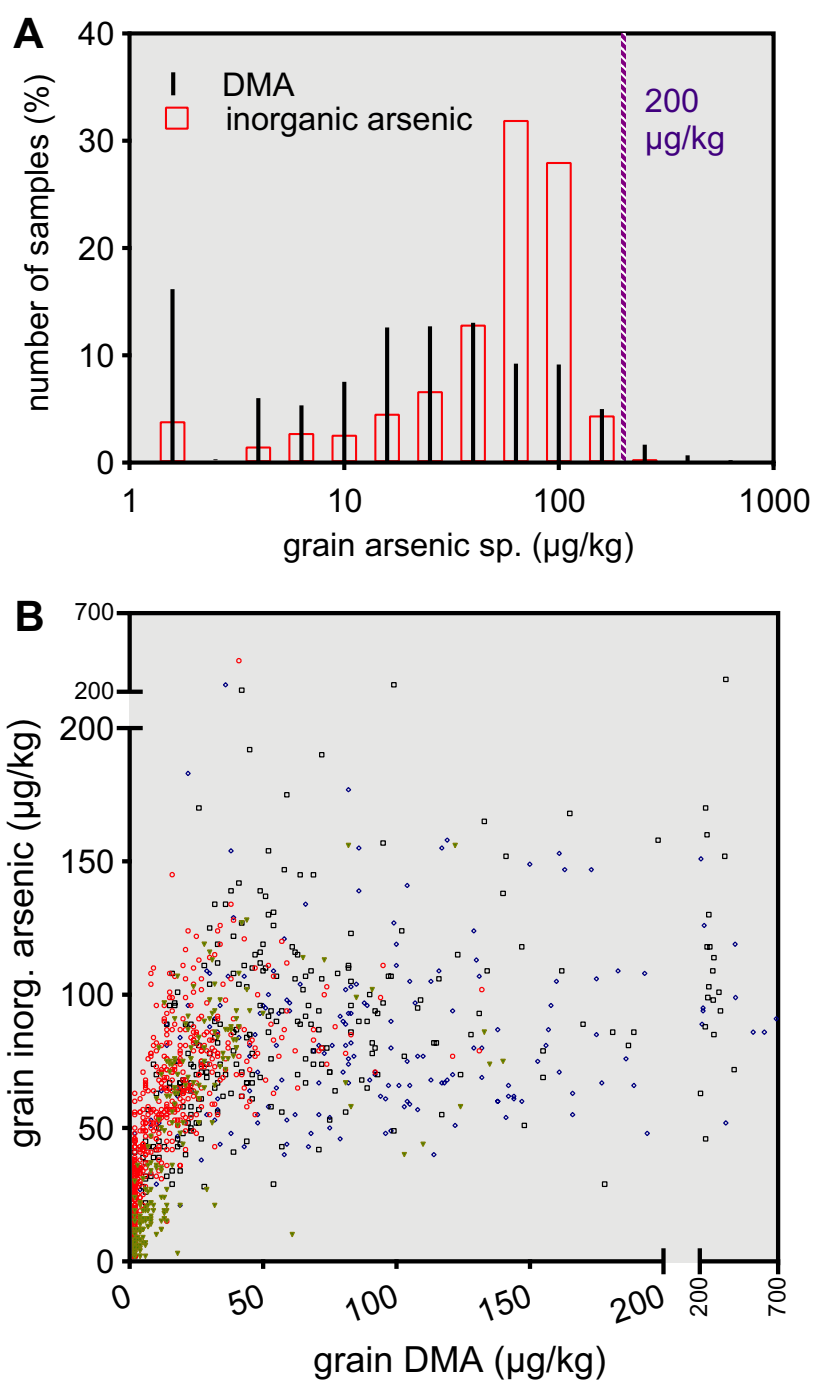

Fig. 2 Relationships between inorganic arsenic and DMA in grain from the global survey: distribution of inorganic arsenic versus DMA for all the samples (a), and relationship between inorganic arsenic and DMA in individual samples, with each point labelled as for Fig. 2 (b)

Asian and European temperate regions also had high DMA

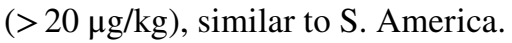

The distribution of inorganic arsenic and DMA in global rice is shown in Fig. 2. There is a peak at $<2 \mu \mathrm{g} / \mathrm{kg}$ for both inorganic arsenic and DMA, below the LoD. Besides the samples below LoD, both species followed a unimodal distribution. For DMA this distribution was normal, but for inorganic arsenic it was asymmetric, skewed towards higher concentrations. However, the DMA curve was more extended with respect to higher concentrations. A plot of inorganic arsenic versus DMA for the entire global dataset showed that inorganic arsenic dominated when the sum of inorganic arsenic and DMA was low, but this situation reversed at higher grain concentrations (Fig. 2). The higher grain concentrations are dominated by South American and
Mediterranean rice production regions, which can reach up to $700 \mu \mathrm{g} / \mathrm{kg}$ DMA. South East Asian and African rice never exceeded $150 \mu \mathrm{g} / \mathrm{kg}$ DMA.

\section{Discussion}

This current investigation has identified that only eastern hemisphere, southern latitude rice production regions have low-grain inorganic arsenic. In contrast, rice from the Americas was universally elevated in arsenic, with little geographical variation. The concentrations reported in the literature from surveys of Asia (Chen et al. 2018; Williams et al. 2006; Zavala et al. 2008), West Africa (Adeyemi et al. 2017; Adomako et al. 2011), Europe (Signes-Pastor et al. 2016; Sommella et al. 2013) and the USA (Williams et al. 2007; Zavala et al. 2008) are similar to what we report here.

There has been limited survey of arsenic in African rice (Adeyemi et al. 2017; Adomako et al. 2011; Joy et al. 2017). The finding that East African rice is low in arsenic confirms a study which reported that Malawian paddy rice was particularly low in total arsenic (Joy et al. 2017). The underlying geology of the East African region surveyed, stretching from southern Malawi to northern Tanzania, has a diverse topology and geology (McConnell 1972), yet is universally low in inorganic arsenic. East African rice production tends to be low-input and rain-fed (Meerens et al. 2003). As such East African rice production will have limited input from irrigation waters (Williams et al. 2006), pesticides (Williams et al. 2007) and fertilizers (Hartley et al. 2013; Zhuang and McBride 2013).

The widespread of elevation of arsenic in rice throughout South America reported here equates to previous more spatially limited investigations, such as those for Argentina (Farias et al. 2015), South Brazil (Segura et al. 2016) and Ecuador (Otero et al. 2016). From the current study, and from literature investigations (Meharg et al. 2009; Zavala et al. 2008), the South American rice grain inorganic arsenic concentrations are similar to those found through the major rice growing belts of S.E. Asia and Europe.

A Chinese study found no trend in inorganic arsenic from south to north of that county (Chen et al. 2018). The DMA versus inorganic arsenic relationships found for Chinese rice confirmed our finding that DMA was prevalent at higher sums of arsenic species in grain (Chen et al. 2018). Both South American (as reported here) and North American (Meharg et al. 2009; Zavala et al. 2008) rice production regions also had elevated grain DMA. The underlying regulation of DMA in soils will be related to the balance between methylation/demethylation (Yoshianga et al. 2011), and to different paddy management regimens (Norton et al. 2013). The paddy soils of the America's are generally managed using directly sowed rice, where those of Africa and Asia 
are dominated by transplanted rice. These have very different water management regimes, which regulates both soil redox and rice rooting patterns (Farooq et al. 2011). Redox is a strong regulator of both arsenic availability in soils and of methylation activity (Meharg and Zhao 2012; Norton et al. 2013; Reid et al. 2017; Yoshianga et al. 2011). Having identified major global trends in DMA production provides impetus to identifying the factors involved in soil microbial methylation of arsenic. Sri Lankan rice was the only country that had an anomalous DMA profile, being low despite having moderate inorganic arsenic concentrations. Sri Lanka was surveyed across that country's diverse climate, geology and topology (De Silva et al. 2007), with paddy cultivation systems that traverse from lowland irrigated systems to upland rain-fed Meharg and Raab 2010). Sri Lankan rice is relatively high in inorganic arsenic but low in DMA. This suggests that upland/lowland cultivation of rice, per se, does not seem to be a major determinant of grain inorganic or DMA concentrations. However, more fine-scale investigations are required to investigate more subtle differences between Sri Lankan paddy agroecosystems.

MLs have been set for inorganic arsenic rice at $200 \mu \mathrm{g} / \mathrm{kg}$ by both the EU (EU 2015) and WHO (2014). Only 5 out of 1180 samples analysed, $0.4 \%$ of samples, failed these limits. The considerations on the suitability of these standards have been made elsewhere by the authors (Carey et al. 2018; Meharg and Raab 2010). The concentrations of inorganic arsenic present in the global supply-chain are problematic in the EU for the infant standard $(100 \mu \mathrm{g} / \mathrm{kg})$, which is half the adult standard (EU 2015). From our study $17.6 \%$ of rice grain samples would fail this infant standard. Note that the standard is set at the concentration of inorganic arsenic in the rice used in formulating infant products, rather than in the final concentration of those products. That is, $17.6 \%$ of rice in the global supply chain cannot be used for infant foods in the EU.

This knowledge garnered in this current study adds to our understanding of geographically limited surveys that compare the variation in arsenic speciation between growing regions (Meharg et al. 2009; Zavala et al. 2008), and more limited regional studies that have been conducted (for example: Adeyemi et al. 2017; Adomako et al. 2011; Farias et al. 2015; Joy et al. 2017; Otero et al. 2016; Segura et al. 2016). Specifically, the current findings of this show that given the correct growing environment paddy rice can be low in inorganic arsenic. Southern hemisphere, at eastern latitudes, is the location that low arsenic rice can be sourced for products for sub-populations where arsenic exposure is of concern, such as for infant foods (Carey et al. 2013). Identifying why East African and Southern Indonesian rice cultivation are outliers with respect to rice globally will hold the clues of how to produce low arsenic rice elsewhere. This may include climate, geology, cultivation practice and any potential pollution sources. It also ascertains that S. American rice is high in arsenic species and opens up important considerations about elevation in DMA in certain growing regions.

Acknowledgements We thank Edward Joy for the Malawian samples used in this study.

Open Access This article is distributed under the terms of the Creative Commons Attribution 4.0 International License (http://creativeco mmons.org/licenses/by/4.0/), which permits unrestricted use, distribution, and reproduction in any medium, provided you give appropriate credit to the original author(s) and the source, provide a link to the Creative Commons license, and indicate if changes were made.

\section{References}

Adeyemi JA, Adedire CO, Martins-Junior AC, Paulelli AC, Awopetu AF, Segura FR, de Oliveira-Souza VC, Batista B, Barbosa F Jr (2017) Arsenic speciation in rice consumed in south-western Nigeria, and estimation of dietary intake of arsenic species through rice consumption. Toxicol Environ Chem 99:999-1006

Adomako EA, Williams PN, Deacon C, Meharg AA (2011) Inorganic arsenic and trace elements in Ghanaian grain staples. Environ Pollut 159:2435-2442

Carey A-M, Scheckel KH, Lombi E, Newville M, Choi Y, Norton G, Charnock JM, Feldmann J, Price AH, Meharg AA (2010) Grain unloading of arsenic species in rice. Plant Physiol 152:303-319

Carey M, Donaldson E, Signes-Pastor AJ, Meharg AA (2018) Dilution of rice with other gluten free grains to lower inorganic arsenic in foods for young children in response to European Union regulations. PLoS ONE 13:e01947000

Chen H, Tang Z, Wang P, Zhao FJ (2018) Geographical variations of cadmium and arsenic concentrations and arsenic speciation in Chinese rice. Environ Pollut 238:482-490

De Silva CS, Weatherhead EK, Knox JW, Rodriguez-Diaz JA (2007) Predicting the impacts of climate change-a case study of paddy irrigation water management requirements in Sri Lanka. Agric Water Manag 93:19-39

EFSA (2009) Panel on Contaminants in the Food Chain (CONTAM)/ Scientific opinion on arsenic in food. EFSA J 7:1351

EU (2015) Commission Regulation 2015/1006 of 25 June 2015 amending Regulation (EC) No 1881/2006 as regards maximum levels of inorganic arsenic in foodstuffs

Farias SS, Londonio A, Quintero C, Befani R, Smichowski P (2015) On-line speciation and quantification of four arsenical species in rice samples collected in Argentina using a HPLC-HG-AFS coupling. Microchem J 120:34-39

Farooq M, Siddique KHM, Rehman H, Aziz T, Lee DJ, Wahid A (2011) Rice direct seeding: experiences, challenges and opportunities. Soil Till Res 111:87-98

Hartley TN, Macdonald AJ, McGrath SP, Zhao FJ (2013) Historical contamination of soil due to long-term phosphate fertilizer applications. Environ Pollut 180:259-264

Joy EJM, Ander EL, Broadley MR, Young SS, Chilimba ADC, Hamilton EM, Watts MJ (2017) Elemental composition of Malawian rice. Environ Geochem Health 39:835-845

Li P, Zhi YY, Shi JC, Zeng LZ, Wu LS (2015) County-scale temporal-spatial distribution and variability tendency of heavy metals in arable soils influenced by policy adjustment during the last decade: a case study of Changxing, China. Environ Pollut Res 22:17937-17947 
McConnell GSA (1972) Geological development of the rifts system of Eastern Africa. GSA Bull 83:2549-2572

Meerens HCG, Kajiru GJ, Ndege LJ, Enserink HJ, Brouwer J (2003) Evaluation of on-farm soil fertility research in the rainfed lowland rice fields of Sukumaland, Tanzania. Exp Agric 39:65-79

Meharg AA, Raab A (2010) Getting to the bottom of arsenic standards and guidelines. Environ Sci Technol 44:4395-4399

Meharg AA, Zhao F-J (2012) Arsenic \& rice. Springer, Berlin

Meharg AA, Williams PN, Adomako E, Lawgali YY, Deaon C, Villada A, Cambell RCJ, Sun G, Zhu YG, Feldmann J, Raab A, Zhao FJ, Islam R, Hossain S, Yanai J (2009) Geographical variation in total and inorganic arsenic content of polished (white) rice. Environ Sci Technol 43:1612-1617

Norton GJ, Adomako EE, Deacon CM, Carey AM, Price AH, Meharg AA (2013) Effect of organic matter amendment, arsenic amendment and water management regime on rice grain arsenic species. Environ Pollut 177:38-47

Otero XL, Tierra W, Atiga O, Guanolusia D, Nunes LM, Ferreira TO, Ruales J (2016) Arsenic in rice agrosystems (water, soil and rice plants) in Guayas and Los Rios provinces, Ecuador. Sci Tot Environ 573:778-787

Reid MC, Maillard J, Bagnoud A, Falquet L, Vo PL, Bernier-Latmani R (2017) Arsenic methylation dynamics in a rice paddy soil anaerobic enrichment culture. Environ Sci Technol 51:10546-10554

Segura FS, Souza JMD, De Paula ES, Martins AD, Pauleli ACC, Barbosa F, Batista BL (2016) Arsenic speciation in Brazilian rice grains organically and traditionally cultivated: is there a difference in arsenic content? Food Res Int 89:169-176

Signes-Pastor AJ, Carey M, Carbonell-Barrachina AA, Moreno-Jimenez E, Green AJ, Meharg AA (2016) Geographical variation in inorganic arsenic in paddy field samples and commercial rice from the Iberian Peninsula. Food Chem 202:356-363
Sommella A, Deacon C, Norton G, Pigna M, Violante A, Meharg AA (2013) Total arsenic, inorganic arsenic, and other element concentrations in Italian rice grains with origin and type. Environ Pollut 181:38-43

WHO (2014) Codex Alimentarius Commission, 37th Session, Geneva, 14-18 July 2014

Williams PN, Islam MR, Adomako EE, Raab A, Hossain SA, Zhu YG, Feldmann J, Meharg AA (2006) Increase in rice grain arsenic for regions of Bangladesh irrigating paddies with elevated arsenic in groundwaters. Environ Sci Technol 40:4903-4908

Williams PN, Raab A, Feldmann J, Meharg AA (2007) Market basket survey shows elevated levels of As in south central U.S. processed rice compared to California: consequences for human dietary exposure. Environ Sci Technol 41:2178-2183

Yoshianga M, Ca Y, Rosen BP (2011) Demethylation of methylarsonic acid by a microbial community. Environ Microbiol 13:1205-1215

Zavala YJ, Gerads R, Gurleyuk H, Duxbury JM (2008) Arsenic in rice II. Arsenic speciation in USA grain and implications for human health. Environ Sci Technol 42:3861-3866

Zhu Y-G, Sun GX, Lei M, Teng M, Liu YX, Chen NC, Wang LH, Carey AM, Deacon C, Raab A, Meharg AA, Williams PN (2008) High percentage inorganic arsenic content of mining impacted and nonimpacted Chinese rice. Environ Sci Technol 42:5005-5013

Zhuang P, McBride MB (2013) Changes during a century in trace element and macronutrient concentrations of an agricultural soil. Soil Sci 178:105-106

Publisher's Note Springer Nature remains neutral with regard to jurisdictional claims in published maps and institutional affiliations. 